\title{
A MOTIVATION BASED SHOPPER TYPOLOGY FOR SHORT TERM RETAIL EVENTS
}

\author{
ZITA KELEMEN - ILDIKÓ KEMÉNY² \\ ${ }^{1}$ Department of Marketing Research and Consumer Behaviour, \\ Corvinus University of Budapest, Hungary \\ Email: zita.kelemen@uni-corvinus.hu \\ ${ }^{2}$ Department of Marketing Research and Consumer Behaviour, \\ Corvinus University of Budapest, Hungary
}

The study focuses on the analysis of a short term retail event. Its success is similar to Black Friday, but differs in underlying consumer motivations. Using a mixed methodology, phenomenological interviews provided in-depth understanding of the participants' lived experiences followed by an online survey with a sample size of 761 respondents. Exploratory factor analyses has been used to differentiate three distinctive groups with hierarchical cluster analysis. By adopting the ANOVA method, clusters and hypothesis were further analysed. This study is the first to employ quantitative study for a shopper taxonomy of such an event. Our results contribute valuable insights into retail shopping orientation and shopper taxonomic scheme literatures. The finding that a short term retail event's shoppers form distinct groups of consumers indicates a new way of customers embracing retail events. Our research has identified three distinct shopper clusters based on the different weight of task and social orientations: Loyalists, Enthusiasts, Newbies. Each group applies different strategies to satisfy personal goals. The present shopper taxonomy offers new strategic ways to increase retail performance by targeting the most valuable customers.

Keywords: shopper taxonomy, task and social shopping orientation, shopper segmentation, consumer behaviour

JEL-codes: M16, M31 


\section{INTRODUCTION}

Better employment opportunities have increased the financial independence of women and their spending power. Thus today, women play an increasing role in decision making which has resulted in dramatic changes in their consumer values and practices. Due to the strong development of the distribution sector, women today have many options to shop. Thus retailers need to understand the drivers and motivations behind their decisions to ensure their share of wallet. The purpose of this paper is to understand the behaviour of consumers during a short term coupon based retail event: the Glamour Days (GD). Introduced by the Hungarian edition of Glamour Fashion Magazine, GD has been serving as an exclusive and extremely popular shopping event targeting women since 2005. GD was the first shopping event in Hungary that enabled consumers to purchase a wide range of products at a discount with coupons provided by the fashion magazine. For two weekends a year, GD allows its participants to buy their favourite brands, more than 320 brands, at reduced prices, but perhaps even more importantly, it exposes consumers to various hedonistic, impulse as well as self-gifting shopping experiences, that in turn challenges former consumer values and preferences. By attracting tens of thousands of consumers each year, this event serves as a unique opportunity for consumers wishing to fully immerse in a dedicated day for shopping, turning it into a new "cultural phenomenon" rather than just another retail promotional event. But it is not only about consumers. The overall expenditure is close to Christmas shopping revenues, thus retailers eagerly look forward to these days in order to achieve a strong financial performance before the end of the year Christmas period (in April and October). Understanding the shopping habits of the participants will better allow retailers to target their heavy buyers and loyal customers along with new ones.

Earlier research focused on holiday shopping and Black Friday periods (Boyd Thomas - Peters 2011), but consumer behaviour during important short term - but not festive - shopping periods has not been examined in depth. GD may be considered similar to Black Friday shopping, but as mentioned, it is not related to holiday shopping as Black Friday (Swilley - Goldsmith 2012; Smith - Raymen 2017), and it does not represent “deviant leisure”. Smith and Raymen (2017: 392) refer to deviant leisure as "leisure activities of constituent parts thereof which have the capacity to cause harm". The authors explain that the attachment of "social value" to the acquisition and display of consumer goods became a source of self-determination and results in an overall competition for desired goods. Such attitudes drive individuals towards behaviours that allow social norms to be overwritten and result in violent actions. 
Our paper investigates GD to understand if groups of consumers - based on similar shopping motivations - could be identified for an event that is not driven by festive shopping goals and although closely relates to self-identity expression, it does not generate deviant or violent behaviour among its consumers. The results of our research present new opportunities to create retail events that may be introduced independently from holiday periods, providing high sales value and still offering an opportunity for co-creation of a socially engaging event without the risk of deviant shopper behaviour.

The paper is organized as follows. First, the paper presents the contemporary theories of shopping orientation and underlying motivational drivers, hedonistic values including impulse buying, with particular attention to the ways these concepts may help practitioners and professionals alike to gain a better understanding of consumerism within special retailer events. Second, this study introduces a large-scale quantitative research, based on which three shopper typologies have been identified based on their shopping orientation and accompanying buying strategies. The appeal of such taxonomic schemes is their power to enable retailers to better reach or even differentiate their customer base, and customize their marketing strategy. Finally, implications for companies wishing to target consumers in a short period retail sales event along are discussed, along with directions for future research.

\section{THEORY AND HYPOTHESES}

Women love shopping (Fischer - Arnold 1994) and have higher hedonistic motivations than men (Arnold - Reynolds 2003; Wesley et al. 2006). The basic motivations for shopping behaviour were identified by Tauber as early as 1972, describing different psychological needs divided into two main fields: personal and social drivers. Considerable research has been also devoted to the understanding of consumer shopping motivations. Shopping orientation is defined as "a person's mental framework of responses designed to navigate the shopping environment to achieve personal goals” (Baker - Wakefield 2012: 793.) Prior research has identified two fundamental orientations: hedonic and utilitarian.

In contrast to utilitarian consumption which can be viewed as a task-related and rational activity (Dhar - Wertenbroch 2000), Hirschman and Holbrook (1982: 92) argue that hedonic consumption "designates those facets of consumer behaviour that relate to the multi-sensory, fantasy and emotive aspects of one's experience with products". Hedonic experiences hold stimulative and experiential values for consumers (Wakefield - Baker 1998), and therefore it is considered to be a more 
subjective and personal experience when compared to utilitarian consumption. Moreover, shopping incorporates various activities that may provide hedonistic and utilitarian value at the same time (Belk 1987; Fischer - Arnold 1990; Sherry 1983). Hedonic consumption, not surprisingly, has close linkages with pleasureseeking and pleasure-maximizing (Alba - Williams 2013); fantasies and arousal (Arnold - Reynolds 2012); avoiding unpleasant emotions (Goldsmith et al. 2012) as well as engaging in joyful activities (Zhong - Mitchell 2012). However, consumers may exhibit both task- and social based consumer orientation. Evidence from prior research proved that consumers will engage in one or the other motivation (Bloch et al. 1994; Leonadri - Gonida, 2007) and called for further research of shoppers exhibiting both orientations to understand the distinct responses of such groups to the shopping environment (Baker - Wakefield 2012). Studies related to goal theory also suggest that in most cases task orientation declines as social orientation increases (Midgley et al. 1995; Baker - Wakefield 2012). According to Arnold and Reynolds (2003), the knowledge of distinct customer segments is not only useful for retailers in constructing marketing communication strategies, but enables them to assess the motivational strength of different shopper groups. Thus, we examine this argument with regards to the orientation of shoppers visiting GD. Consequently, we propose the following:

H1: The shopping orientation of GD consumers is positively related to both social and task related descriptive factors.

Field theory proposes the notion of one's "life-space", the interdependency between person and environment (Lewin 1939; Baker - Wakefield 2012). Time is also an essential part of this framework, as one must organize time with relation to the expected physical environment. GD being a short term opportunity for shopping at a discount, creates a crowded environment for participants, by which time becomes a key factor in achieving one's goals.

Josephs et al. (1992) argue that for women, social interaction is a basis for selfesteem, thus viewing certain retail settings as an opportunity to socialize. Recalling the quote from a participant in our exploratory phenomenological interview: "You have to dress up for the GD, as it is not only about shopping, but it's a program like going to the cinema." Social shopping is defined as "the enjoyment of shopping with friends and family, socializing and bonding with others while shopping” (Arnold - Reynolds 2003: 80; Babin et al. 1994). Research on Black has focused on the hedonic experience which relates to spending quality time with family members and gaining as much financial advantage as possible. GD consumers exhibit hedonic experience by self-congruence and the advantage provided by coupons is less of a utilitarian value compared to Black Friday shopping. 
The main objective of all shopper typologies is to categorize customers into certain groups in order to help retailers to achieve their strategic goals, be it related to profit, new customer acquisition or better targeting. Westbrook and Black (1985) offer a wide review of the literature about shopper taxonomies and extend it by six clusters based on the differences in shopping motivations. Black Friday shoppers have also been categorized based on this experience. Based on previous research, it is suggested that GD shoppers may also form distinct groups, therefore the following hypothesis was formed:

H2: GD shoppers can be categorized into significantly differing groups based on their shopping orientation.

Considerable research has been devoted to the desire of social interaction while shopping, resulting in substantial approaches to shopper typologies. Therefore it is suggested that GD consumers might be distinguished based on a number of factors related to their level of task- or social orientation. Hence:

H3: Social orientation with regard to Glamour Shopping Days positively relates to experienced shoppers.

Impulse buying is closely related to hedonic consumption. Rook (1987: 191) defines impulse buying as it "occurs when a consumer experiences a sudden, often powerful and persistent urge to buy something immediately. The impulse to buy is hedonically complex and may stimulate emotional conflict". Impulse buying can be characterized by rapid decision-making and a strong need to acquire immediate possession while paying little or no attention to potential negative consequences (Kacen - Lee 2002). Buying impulses are also culture-specific in nature, demonstrating that consumers may differ in how they engage in impulse buying practices (Rook 1987; Kacen - Lee 2002). In addition, albeit impulse buying often invokes negative feelings, such as shame or guilt, consumers do not necessarily view it as a "bad" activity. Previous research portrayed that impulse buying is also enhanced by environmental clues. Certain settings, such as sales events, are more likely to encourage consumers to engage in impulse buying than other activities (Rook - Fisher 1995).

Considerable research has been devoted to suggestions to retailers on what to do to attract or better serve consumers. The limited academic literature that was devoted to the investigation of "strategies" that consumers develop in order to succeed and satisfy their motivations, were linked to festive periods such as Black Friday. Our research focuses on a non-festive short term retail purchasing situation that is possible to recreate as it attracts women by offering a few days 
dedicated to shopping. Baker and Wakefield (2012) argue that task shoppers have a higher need for control and view crowd as a stressful factor, in contradiction with social shoppers who in turn feel excited and are not bothered by the crowd. We suggested that GD consumers exhibit both: task and social orientation during the event implying different behaviour related to different needs. At the same time fashion items are highly hedonic products with relation to self-esteem management, therefore it is increasingly important that long awaited items are obtained along with the preference for the intimacy of people with the same interest in the mall. Black Friday shopping strategies and rituals have already been identified, focusing on securing blockbuster deals and emphasizing the importance of familial bonds. Black Friday is a collective consumption ritual that is shared among family members and friends resulting in planned strategies and tactics. Therefore we have developed the below hypothesis to understand whether GD shoppers also form strategies:

H4. GD shoppers have different strategies to ensure the need for control to avoid the crowd and secure the successful purchase.

The objective of the current paper is also to investigate whether such strategies are descriptive to certain groups of consumers and if GD may be considered as a collective family event. The paper also intended to provide recommendations on how retailers may integrate such consumer driven strategies into their retail tactics.

\section{METHODOLOGY}

\subsection{Procedure}

In order to provide a comprehensive exposition of the research question with regard to consumers' behaviour during GD, the paper applied a mixed method design (Morse 2003; Neulinger 2016). The qualitative and quantitative phase was conducted sequentially. First, the qualitative research was implemented by using phenomenological interviewing techniques to gain a deeper understanding of the multiple perspectives on participants' "lived experience" (Spiegelberg 1982). Participants were selected based on personal judgement and snowball sampling. As a result, phenomenological interviews were conducted with 18 experienced GD women shoppers between the ages of 16-35. Unstructured in-depth interviews varied in length between 45-90 minutes, and were conducted the week after the Glamour Days shopping weekend. Based on the results of this explor- 
atory phenomenological research (Kelemen et al. 2016) we have developed a quantitative study to understand how these experiences may be applied to the total population of the event. The main experiences included preparation, forming strategies, execution and racing with other customers along with sharing war stories and "trophies". The questionnaire was developed in order to understand how much these experiences may describe GD shoppers overall and if there are typologies to be set based on the differences. The research was carried out during a two year period.

Our initial scale is based on the hedonic and utilitarian shopping value scale (Babin et al. 1994) and the impulse buying behaviour scale developed by Hausman (2000), incorporating items from our interview data. The initial pool of items was tested online for a week and modifications were made to several items to create our final scale.

The results of the qualitative and quantitative data were analysed separately, and were integrated at the interpretative level of the research (Teddlie - Tashakorri 2003).

\subsection{Participants}

Data for the research was obtained on the Facebook page of Glamour Magazine, just after Glamour Shopping Days. 761 people were reached. All data were handled anonymously and confidentially. Since GD target primarily women consumers, the final sample consisted of 579 women shoppers, between the ages of 18 and 35 , with an average age of 24.9 years $(s=7.25)$. In terms of family status, $85 \%$ of the respondents had no children, therefore our participants were mainly young and independent adults. $93.2 \%$ of the respondents have already participated in the GD at least once, with $63.6 \%$ having already visited the event at least 4 times.

\subsection{Measures}

The survey for the present study was formulated on the basis of the relevant literature (Babin et al. 1994; Hausman 2000; Boyd - Peters 2011) as well as the results from the in-depth interviews with Glamour Days shoppers. Our final scale consisted of 31 items. Exploratory factor analysis revealed an eight-factor structure of the items. The first one captures the process of shopping (shopping process factor, 6 items), while the second factor covers strategies implemented to secure items previously included on the wish list (securing purchase, 4 items). The third and fourth factors were joy of shopping (sharing emotions linked to new purchases factor, 3 items) and intention of sharing coupons with others (sharing coupons, 3 items). The fifth, sixth and seventh factors encapsulate utilitarian and 
hedonistic shopping values (5 items), planned impulsiveness (3 items), and the feeling of guilt related to overspending ( 2 items). Finally, the eighth factor refers to items explaining the choice of accompanying person specifically for GD (5 items). All items were measured using seven-point Likert type scales.

\section{RESULTS}

\subsection{Shopper categorization based on the strategies executed on Glamour Days}

Consumer strategies were measured using 10 items calculated by the previously presented factor analysis. Results suggest that participants were likely to collect coupons $(m=6.19)$ as well as plan their purchases $(m=5.76)$ prior to their trip to GD. They tended to do the shopping on the first day of the event $(\mathrm{m}=5.31)$. Consumers were likely to have a utilitarian approach towards the GD such as preparing for the event or arriving at the shops on time but they were less likely to visit the shops to try on clothes before GD (Table 1).

Table 1. Constructs and descriptives

\begin{tabular}{l|l|c|c}
\hline \multirow{2}{*}{} & & \multicolumn{2}{|c}{ Total (N =579 people) } \\
\cline { 3 - 4 } & & Mean & $\begin{array}{c}\text { Std. } \\
\text { Deviation }\end{array}$ \\
\hline \multirow{4}{*}{$\begin{array}{l}\text { Strategies for the shopping } \\
\text { procedure/trip (SHPROC) }\end{array}$} & I cut coupons out in advance & 6.19 & 1.61 \\
\cline { 2 - 4 } & I try to plan my GD trip in advance & 5.76 & 1.59 \\
\cline { 2 - 4 } & I try to go on the first day & 5.31 & 1.98 \\
\cline { 2 - 4 } & I search the internet in advance & 4.14 & 2.21 \\
\cline { 2 - 4 } & I make a wish list & 4.04 & 2.39 \\
\cline { 2 - 4 } & I try to get there by store opening & 3.38 & 2.35 \\
\hline \multirow{4}{*}{$\begin{array}{l}\text { Secure most important } \\
\text { items to buy (SECPROC) }\end{array}$} & I wait out with purchase for GD to come & 5.07 & 1.86 \\
\cline { 2 - 4 } & I do not plan purchases & 3.32 & 1.99 \\
\cline { 2 - 4 } & I try items on before GD & 2.89 & 2.16 \\
\cline { 2 - 4 } & I have it put away in the store for GD & 1.82 & 1.50 \\
\hline
\end{tabular}

Source: authors

Based on the results of the factor analysis, the current study employed hierarchical cluster analysis to identify consumer groups. Using Ward's method, three consumer groups were identified: the Loyalists $(\mathrm{N}=144)$, the Enthusiasts $(\mathrm{N}=201)$, and Newbies $(\mathrm{N}=234)$. 
Table 2. Shopper clusters' strategies

\begin{tabular}{|c|c|c|c|c|c|c|c|c|c|}
\hline & & \multicolumn{2}{|c|}{$\begin{array}{c}\text { Loyalists } \\
\text { (N = 144 } \\
\text { people) }\end{array}$} & \multicolumn{2}{|c|}{$\begin{array}{c}\text { Enthusiasts } \\
\text { ( } \mathrm{N}=201 \\
\text { people) }\end{array}$} & \multicolumn{2}{|c|}{$\begin{array}{c}\text { Newbies } \\
(\mathrm{N}=234 \\
\text { people }\end{array}$} & \multicolumn{2}{|c|}{$\begin{array}{c}\text { Total } \\
(\mathrm{N}=579 \\
\text { people })\end{array}$} \\
\hline & & Mean & $\begin{array}{l}\text { Std. } \\
\text { dev. }\end{array}$ & Mean & $\begin{array}{l}\text { Std. } \\
\text { dev. }\end{array}$ & Mean & $\begin{array}{l}\text { Std. } \\
\text { dev. }\end{array}$ & Mean & $\begin{array}{l}\text { Std. } \\
\text { dev. }\end{array}$ \\
\hline \multirow{6}{*}{$\begin{array}{l}\text { Strategies for } \\
\text { the shopping } \\
\text { procedure/trip } \\
\text { (SHPROC) }\end{array}$} & $\begin{array}{l}\text { I cut coupons } \\
\text { out in advance }\end{array}$ & 6.87 & 0.49 & 6.36 & 1.43 & 5.63 & 1.97 & 6.19 & 1.61 \\
\hline & $\begin{array}{l}\text { I try to go on the } \\
\text { first day }\end{array}$ & 6.72 & 0.75 & 5.56 & 1.74 & 4.24 & 2.07 & 5.31 & 1.98 \\
\hline & $\begin{array}{l}\text { I try to plan } \\
\text { my GD trip in } \\
\text { advance }\end{array}$ & 6.66 & 0.79 & 6.07 & 1.25 & 4.93 & 1.81 & 5.76 & 1.59 \\
\hline & $\begin{array}{l}\text { I make a wish } \\
\text { list }\end{array}$ & 6.17 & 1.24 & 5.03 & 1.95 & 1.87 & 1.25 & 4.04 & 2.39 \\
\hline & $\begin{array}{l}\text { I search the in- } \\
\text { ternet in advance }\end{array}$ & 5.82 & 1.45 & 4.40 & 2.07 & 2.88 & 1.94 & 4.14 & 2.21 \\
\hline & $\begin{array}{l}\text { I try to get there } \\
\text { by store opening }\end{array}$ & 5.68 & 1.64 & 3.64 & 2.26 & 1.73 & 1.28 & 3.38 & 2.35 \\
\hline \multirow{4}{*}{$\begin{array}{l}\text { Secure most } \\
\text { important } \\
\text { items to buy } \\
\text { (SECPROC) }\end{array}$} & $\begin{array}{l}\text { I wait out with } \\
\text { purchase for GD } \\
\text { to come }\end{array}$ & 6.22 & 0.93 & 4.95 & 1.91 & 4.45 & 1.93 & 5.07 & 1.86 \\
\hline & \begin{tabular}{|l|} 
I try items on \\
before GD \\
\end{tabular} & 4.09 & 2.34 & 2.96 & 2.09 & 2.10 & 1.71 & 2.89 & 2.16 \\
\hline & $\begin{array}{l}\text { I have it put } \\
\text { away in the store } \\
\text { for GD }\end{array}$ & 2.81 & 2.13 & 1.58 & 1.16 & 1.42 & 0.90 & 1.82 & 1.50 \\
\hline & $\begin{array}{l}\text { I do not plan } \\
\text { purchases }\end{array}$ & 2.07 & 1.50 & 3.15 & 1.82 & 4.22 & 1.96 & 3.32 & 1.99 \\
\hline
\end{tabular}

Source: authors

The results of the cluster analysis largely support our $\mathrm{H} 2$ hypothesis, as three strongly distinctive consumer groups were identified (Table 2). Below we introduce the shopping behaviour of the different customer groups.

\subsection{Loyal consumers}

Loyal consumers represent the smallest group. They were likely to plan their purchases $(\mathrm{m}=6.66)$, wrote a wish-list $(\mathrm{m}=6.17)$ and tried on clothes before the GD $(\mathrm{m}=4.09)$ (Table 3). Time management was an important factor for this group of consumers. It was closely linked to task related strategies to ensure successful purchase after which they could enjoy the social aspect of the event.

Not surprisingly, they have attended more GD than Enthusiasts or Newbies $(\mathrm{m}=5.31)$, and they tended to take part in the event alone (30\%) (Table 4). For this latest factor, differences are significant $\left(\operatorname{chi}^{2}(20)=37.10, \mathrm{p}=0.041\right)$ between 
groups. As expected, one of the strategies applied by Loyalists is to visit GD alone in order to be able to stick to the carefully planned shopping trip (Table 3). At the same time, during shopping they look for possibilities to socialize even by sharing coupons with strangers. During these days, consumers are more open to the interaction with others fuelled by the excitement and common interest of the same event. Black Friday has its own "rules", such as talking to others in the line but not sharing the wish list (Boyd - Peters 2011), while on GD the coupons are necessary to take financial advantage, therefore the coupon book is known and purchased by everyone. GD is not considered as an overall competition among shoppers like Black Friday events, therefore the possibility of deviant behaviour is also less likely. H3 is therefore accepted.

Table 3. With whom do you go to Glamour Days? (more answers possible)

\begin{tabular}{|c|c|c|c|c|c|}
\hline & $\begin{array}{c}\text { Loyalists } \\
(\mathrm{N}=144 \\
\text { people) }\end{array}$ & $\begin{array}{c}\text { Enthusiasts } \\
(\mathrm{N}=201 \\
\text { people }) \\
\end{array}$ & $\begin{array}{c}\text { Newbies } \\
(\mathrm{N}=234 \\
\text { people }\end{array}$ & $\begin{array}{c}\text { Total } \\
(\mathrm{N}=579 \\
\text { people })\end{array}$ & \\
\hline Alone & $30.1 \%$ & $20.4 \%$ & $16.7 \%$ & $21.3 \%$ & \multirow{6}{*}{$\begin{array}{c}\operatorname{Chi}^{2}(20)=37.10 \\
p=0.041\end{array}$} \\
\hline My partner & $13.3 \%$ & $15.4 \%$ & $24.0 \%$ & $18.4 \%$ & \\
\hline My mother & $14.7 \%$ & $21.4 \%$ & $17.6 \%$ & $18.2 \%$ & \\
\hline Other family member & $7.7 \%$ & $9.0 \%$ & $7.7 \%$ & $8.1 \%$ & \\
\hline Friends & $18.9 \%$ & $16.9 \%$ & $20.6 \%$ & $18.9 \%$ & \\
\hline $\begin{array}{l}\text { Whoever has time to } \\
\text { come with me }\end{array}$ & $14.7 \%$ & $16.9 \%$ & $13.3 \%$ & $14.9 \%$ & \\
\hline
\end{tabular}

Source: authors

Impulsivity, understandably, was less pronounced among Loyalists when compared to Enthusiasts or Newbies. As such, they appeared to be planned purchasers, who actively budgeted and strategized their purchases (Table 4).

Findings from the qualitative study suggest that GD is also considered a significant source of a wide range of social experiences, which allow consumers to spend time with their friends and share coupons. When compared with other groups, loyal consumers appeared to articulate more vehemently the positive as well as negative social aspects of GD, and Enthusiasts were more likely to show their newly purchased items to others than Loyalists ( $\mathrm{H} 4, \mathrm{~m}=4.69$; Table 5).

\subsection{Enthusiasts}

Although similarly to loyal consumers, Enthusiasts also tended to collect coupons and plan their purchases, they spent less time on searching for information on the Internet $(\mathrm{m}=4.40)$, writing wish-lists $(\mathrm{m}=5.03)$, and trying on clothes before the $\mathrm{GD}(\mathrm{m}=2.96)$ (Table 3$)$. This group of consumers does not exhibit task orienta- 
Table 4. Other significant differences between groups (1 - fully disagree, 7 - fully agree )

\begin{tabular}{|c|c|c|c|c|c|}
\hline & $\begin{array}{c}\text { Loyalists } \\
(\mathrm{N}=144 \\
\text { people) }\end{array}$ & $\begin{array}{l}\text { Enthu- } \\
\text { siasts (N } \\
=201 \\
\text { people) } \\
\end{array}$ & $\begin{array}{c}\text { Newbies } \\
(\mathrm{N}=234 \\
\text { people }\end{array}$ & $\begin{array}{c}\text { Total } \\
(\mathrm{N}=579 \\
\text { people })\end{array}$ & \\
\hline PLIMP1 - Plan budget for GD & 5.45 & 5.10 & 4.75 & 5.04 & $\begin{array}{c}\text { F-value }(2.574) \\
=8.74 \\
p=0.001\end{array}$ \\
\hline $\begin{array}{l}\text { PLIMP3 - I plan most of the } \\
\text { times }\end{array}$ & 5.62 & 5.36 & 4.19 & 4.95 & $\begin{array}{c}\text { F-value }(2.578) \\
=45.15 \\
p=0.014\end{array}$ \\
\hline $\begin{array}{l}\text { SHAMOT1 - I love showing } \\
\text { my new items to others }\end{array}$ & 4.57 & 4.69 & 4.05 & 4.41 & $\begin{array}{c}\text { F-value(2.573) } \\
=5.70 \\
p=0.004\end{array}$ \\
\hline $\begin{array}{l}\text { SHAMOT2 - I like talking to } \\
\text { others during GD }\end{array}$ & 2.75 & 2.68 & 2.30 & 2.54 & $\begin{array}{c}\text { F-value }(2.573) \\
=4.27 \\
\mathrm{p}=0.014\end{array}$ \\
\hline $\begin{array}{l}\text { SHAMOT3 - I have to hurry } \\
\text { to get items }\end{array}$ & 3.90 & 3.49 & 2.68 & 3.26 & $\begin{array}{c}\text { F-value(2.574) } \\
=19.84 \\
p=0.000\end{array}$ \\
\hline $\begin{array}{l}\text { SHACOUP1 - I have already } \\
\text { shared my coupon at least once }\end{array}$ & 3.67 & 2.98 & 3.01 & 3.17 & $\begin{array}{c}\text { F-value(2.574) } \\
=4.35 \\
\mathrm{p}=0.013\end{array}$ \\
\hline $\begin{array}{l}\text { SHACOUP3 - I would share } \\
\text { my coupons with others }\end{array}$ & 4.97 & 4.61 & 4.43 & 4.63 & $\begin{array}{c}\text { F-value }(2.574) \\
=2.86 \\
p=0.058\end{array}$ \\
\hline
\end{tabular}

Source: authors.

tion as high as Loyalists do, but they still have above average planning for the event. Despite the fact that Enthusiasts were found to engage in self-gifting practices more frequently when compared with Loyalists or Newbies, these results were not significant - the means were nearly identical among the three groups.

\subsection{Newbies}

In contrast to Loyalists and Enthusiasts, Newbies were less likely to plan their purchases $(\mathrm{m}=4.93)$. While they collected coupons, they did not seem to strategize their shopping behaviour (Table 2). Newbies appeared to attend GD with their boyfriends (24\%) or friends (20.6\%) (Table 3) to focus more on the social aspect of the event as they do not have plans in advance. They did not have a priority list of shops to visit or a planned budget or a wish list, therefore are more open to impulse purchasing and visiting of stores (Table 4).

The above results indicate that all GD shopper groups have utilitarian - time management and ensuring the purchase of wish list items - and also social drivers, sharing couponsand excitement withstrangersandfriends. ThereforeH1 isaccepted. 


\section{DISCUSSION}

This study theoretically investigates a coupon based retail event by using quantitative methodology. The importance of the investigation behind GD shoppers' behaviour lies within the fact that it is not related to holidays, and is driven by the need for "me time of women", resulting in high self-related drivers. The quantitative results of our study indicated that GD shoppers are task and social orientated at the same time. A shopper taxonomy was formed on one side based on task driven strategies that shoppers have developed in order to avoid the crowd and to secure items that were important to them; and on the other side based on factors that create excitement. These intense shopping motives have created a strong goal-attainment drive (Dawson et al. 1990) which led to creative tactics employed by participants such as going to the stores to try on items in advance, in order to just "grab and go" the products (knowing it is the right size and fit) during the event. There is a great deal of time spent on the preparation for the event as well. This includes purchasing the magazine as soon as it comes out to the newsstands, cutting out and organizing the coupons, and checking out websites. Based on these preparations, customers plan the route of the shopping trip, forming priorities of obtainable items. This way customers can minimize the time spent on goal specific purchases, and later on can concentrate on the social aspect of the event. In our exploratory interviews, a few participants even mentioned that they go on the first day alone to buy the most important items, and then go back the following day with a friend or their mom for browsing the stores and just enjoying the shopping trip. It is important to mention that there was no mentioning of violence or deviant social behaviour - as during Black Friday shopping (Raymen - Smith 2016), despite similarly large crowds.

Our research has identified three distinct shopper groups based on their motivational strength. The groups differ on the balance between task and social orientation. Although, interestingly all include certain traits of both motivations, their behaviour is significantly different based on the dominance of task or social aspects. Loyalists exhibit both traits the most. Our finding extends previous research results (Baker - Wakefield 2009), by proving that social and task oriented shopping may go hand-in-hand, but consumers will apply strategies to satisfy both expectations. Thus, the knowledge of these shopper segments and their already existing strategies may support retailers in assessing the motivational strength of these different groups. Prior research reported the direct relation between shopping motivations, store preference and brand loyalty, including hedonic and utilitarian shopping value (Babin et al. 1994). As one of the most important goals of retailers is to target heavy users, it is important to know how these customers behave and what their preferences are, being the most loyal cus- 
tomers with the highest life-time-value. GD is an event, which included mostly beauty and fashion brands targeting women. According to prior research, shopping trips focusing on these categories are hedonistic, just as grocery is mostly utilitarian or task oriented. Our study proved that GD has a unique group of customers with strong social and task orientation at the same time. The social aspect of GD is also unique as it shows for example that "loyal consumers" have the highest need for task orientation besides being socially engaged. The fact that a short term retail event limits time to purchase, puts high pressure on experienced participants (Loyalists) to attain their goal. By using their previous experience about the event, they are able to gain competitive advantage over other customers - Enthusiasts and Newbies - in successfully fulfilling their wish lists. Therefore the majority of them decide to go alone or with a carefully chosen friend with the same interest and decision making time, contradicting the expectation that they should have been the most hedonistic consumers of all.

Impulse buying has high value within sales and is closely linked to hedonic buying (Rook 1987). Impulsive purchasing by definition relates to immediate, irresistible buying which help to decline the psychological disequilibrium. In case of GD both Loyalists and Newbies admitted to planed impulsiveness, which means that they know that they will find things that they did not plan. The ambiguous psychological disequilibrium linked to impulse purchasing resulting in feeling of guilt (Rook - Fisher 1985) is negatively associated with GD purchasing. It is considered to be a part of the GD shopping experience. Retailers may also use this knowledge to better prepare and use strategies which are specially tailored to this event to drive impulsiveness of customers being already in a deliberative mindset (Büttner et al. 2013).

\section{IMPLICATIONS FOR RETAILERS}

Apparel retailers need to change their approach to customers to be able to assist both task oriented buyers and social buyers (Beasty 2005). GD is an opportunity for retailers to participate in a coupon based event. The cost of the participation of retailers needs to be managed carefully, but the pay-off is lucrative, if executed well. This body of work has the potential to assist this industry group and professionals in their efforts to develop more efficient ways to reach their customers; to identify segments of the participants with greater accuracy and foresight; and finally to maximize the benefits. Considerable research has given suggestions on how to separately target task or social shoppers (Baker - Wakefield 2012; Arnold - Reynolds 2003; Büttner et al. 2013), but no special indications have been made academically on how to approach customers with both orientations 
during one event. Our study, however, revealed that customers already have a set of strategies in order to satisfy their motivational needs, so the goal of retailers should rather be: how to successfully integrate themselves into these tactics. For instance if a brand does not participate in the coupon book, but offers the same value discount as the coupons at the point of sale during the event, would it be as successful as others which joined the coupon book? We suggest that it is absolutely necessary to join the coupon book. Customers with the highest value (Loyalists) are those who prepare and plan, even save money for GD shopping. Thus, they create a route of priority shops, make a wish list and postpone their gratification by waiting with the purchase for GD. They will spend most of their budget based on the coupons preselected. Hence, although one may think that it is a good idea just to stay out of the coupon book, as people are drawn to the mall anyway, they will likely miss out the opportunity to maximize the potential; and may only reach the Newbies buyer group.

Time and efficiency is a key factor for Loyalists, but also for Enthusiasts. So retailers need to make sure that there are enough sales people to keep order and help at changing rooms or cashiers, as they tend to be the bottlenecks of sales. A good strategy is to hire part-time workers for these three days. Many strategic planners take a day off from work to join in already on the first day. Most of them also visit the stores in advance or check websites. It is a good opportunity to sign up for a loyalty card or VIP membership in exchange for faster check out or early bird opening hours for VIP members. Customers expect the same level of performance even under such extreme crowd and conditions, thus GD is an important tool for brand differentiation and new customer acquisition. Inventory management is a key issue to ensure that goals are achieved and satisfaction is guaranteed, especially on the products that are illustrated in Glamour magazine. Brands, which do not plan well, may disappoint their customers. GD is a hedonic event, and ruining it by not performing well on the expected aspects may hardly be forgiven by customers. Bring a friend type of promotions work well, as the social aspect is very strong within the event. Uniquely, customers may join into such promotions even by sharing a coupon with a stranger to take advantage of offers if they come alone. It is an unorthodox behaviour for Hungarian customers and contradicts behaviour identified for Black Friday shoppers.

Crowd is a major concern of the participants, thus parking at malls becomes a stressful factor already at the beginning of the shopping trip. Brands may sponsor free minibuses (with extra space for luggage), which would run through the city and pick up consumers who intend to attend GD. Not only would this provide stress-free arrival, but would also give the opportunity to socialize and advertise the participation of the brand in the event. 
Sharing the experience about the event and showing off the great product purchases create a strong word-of-mouth in online social media just as well. All groups scored high on this dimension, which leads to great free and independent advertising by customers themselves, providing an opportunity not only to increase shared and earned media presence but also brand building. It is vital for brands to have up-to-date and reliable information on their websites and a Facebook page possibly providing a platform for customer information sharing and enquiry.

As the target group of Glamour Magazine is global, consisting of women who are interested in fashion, there is a possibility of transferring the event to other countries. Our study has proved that even though it seems that all participants have the same attitude towards such a shopping day, the success of sales may largely depend on how much retailers realize that there are indeed significant differences among them, creating unique opportunities. Despite similarities between Black Friday and GD, the major difference lies in the fact that a highly successful retail event maybe created with less discounts and deviant behaviour, but still resulting in similarly high motivations for consumers to shop.

\section{LIMITATIONS AND FUTURE RESEARCH}

We acknowledge the limitations of our research. While we have provided evidence that GD is an important shopping day in retailers' and consumers' calendar alike, its uniqueness may limit the generalizability of our findings. Prior research had already recognized the importance of special shopping days such as Black Friday (Swilley - Goldsmith 2013), with the necessity to extend and test results in other retail settings as well. Our research did not consider the role of store ambiance, such as well-organized store layout, friendliness and professionalism of store personnel, etc. As these factors may interact to alter reactions and perception of the event, future research may explore their role and extend our results. The social orientation of participants includes also the fact of who is chosen as the accompanying person. Twenty percent of the Enthusiasts' group is joined by their mother. The average age of the ample was 24.9 years, young adults, therefore the question arises, whether it is still a part of the socialization process or rather an opportunity for reciprocal socialization (LaPorchia 2015). The relevance of reciprocal socialization should be further investigated, as it may be a new tendency to search for ways of family bonding in the postmodern world. 


\section{REFERENCES}

Alba, J. W. - Williams, E. F. (2013): Pleasure Principles: A Review of Research on Hedonic Consumption. Journal of Consumer Psychology 23(1): 2-18.

Arnold, M. J. - Reynolds, K. E. (2003): Hedonic Shopping Motivations. Journal of Retailing 79(2): 77-95.

Arnold, M. J. - Reynolds, K. E. (2012): Approach and Avoidance Motivation: Investigating Hedonic Consumption in a Retail Setting. Journal of Retailing 88(3): 399-411.

Babin, B. J. - Darden, W. R. - Griffin, M. (1994): Work and or Fun: Measuring Hedonic and Utilitarian Shopping Value. Journal of Consumer Research 20(4): 644-656.

Baker, J. - Wakefield, L. K. (2012): How Consumer Shopping Orientation Influences Perceived Crowding, Excitement, and Stress at the Mall. Academy of Marketing Science 40(6): 791-806

Beatty, S. E. - Ferrell, M. E. (1988): Impulse Buying: Modeling Its Precursors. Journal of Retailing 74(2): 169-191.

Beasty, C. (2005): The Ideal Shopping Experience. www.destinationcrm.com, January 24.

Belk, R. (1987): A Child's Christmas in America: Santa Claus as Deity, Consumption as Religion. Journal of American Culture 10(1): 87-100.

Beverly, J. (1995): Learning to Consume: An Ethnographic Study of Cultural Change in Hungary. Critical Studies in Mass Communication 12(3): 287-305.

Bloch, P. H. - Ridgway, N. M. - Dawson, S. A. (1994): The Shopping Mall as Consumer Habitat. Journal of Retailing 70(1): 23-42.

Boyd, C. O. (2001): Phenomenology the Method. In: Munhall, P. L. (ed.): Nursing Research: A Qualitative Perspective. Sudbury MA: Jones and Bartlett, pp. 93-122.

Boyd, T. J. - Cara, P. (2011): An Exploratory Investigation of Black Friday Consumption Rituals. International Journal of Retail \& Distribution Management 39(7): 522-537.

Büttner, O. - Florack, A. - Göritz, S. A. (2013): Shopping Orientation and Mindsets: How Motivation Influences Consumer Information Processing during Shopping. Psychology and Marketing 30(9): 779-793.

Colaizzi, P. (1978): Psychological Research as a Phenomenologist Views It. In: Valle, R. - King, M. (eds): Existential Phenomenological Alternatives for Psychology. New York, NY: Oxford University Press.

Coulter, R. - Price, L. - Feick, L. (2003): Rethinking the Origins of Involvement and Brand Commitment: Insights from Postsocialist Central Europe. Journal of Consumer Research 30(2): 151-169.

Coulter, R. A. - Price, L. L. - Feick, L. - Micu, C. (2005): The Evolution of Consumer Knowledge and Sources of Information: Hungary Transition. Journal of the Academy of Marketing Science 33(4): 604-619.

Creswell, J. W. (1998): Qualitative Inquiry and Research Design: Choosing among Five Traditions. Thousand Oaks, CA: Sage.

Dawson, S. - Bloch, P. H. - Ridgway, N. M. (1990): Shopping Motives, Emotional States and Retail Outcomes. Journal of Retailing 66(4): 408-427.

Dhar, R. - Wertenbroch, K. (2000): Consumer Choice between Hedonic and Utilitarian Goods. Journal of Marketing Research 37(1): 60-71.

Englander, M. (2012): The Interview: Data Collection in Descriptive Phenomenological Human Scientific Research. Journal of Phenomenological Psychology 43(1): 13-35.

Fischer, E. - Arnold, S. J. (1990): More than a Labor of Love: Gender Roles and Christmas Shopping. Journal of Consumer Research 17(3): 333-345. 
Fischer, E. - Arnold, S. J. (1994): Sex, Gender Identity, Gender Role Attitudes, and Consumer Behaviour. Psychology \& Marketing 11(2): 163-183.

Hausman, A. (2000): A Multi-Method Investigation of Consumer Motivations in Impulse Buying Behaviour. Journal of Consumer Marketing 17(5): 403-426.

Hirschman, E. C. - Holbrook, M. B. (1982): Hedonic Consumption: Emerging Concepts, Methods and Propositions. Journal of Marketing 46(3): 92-101.

Josephs, R. A. - Markus, H. R. - Tafarodi, R. W. (1992): Gender and Self-Esteem. Journal of Personality and Social Psychology 63(3): 391-402.

Kacen, J. J. - Lee, J. A. (2002): The Influence of Culture on Consumer Impulsive Buying Behavior. Journal of Consumer Psychology 12(2): 163-176.

Kaufman, L. - Rousseeuw, P. J. (2005): Finding Groups in Data: An Introduction to Cluster Analysis. New Jersey, NJ: John Wiley \& Sons.

Kelemen, Z. - Nagy, P. - Kemény, I. (2016): How to Transfer a Coupon-Based Event into a Hedonic Shopping Experience? Retail Branding Implications Based on Glamour Shopping Days. Society and Economy 38(2): 219-238.

LaPorchia, C. D. (2015): African American Mother's Socialization of Daughter's Dress and Consumption of Appearance-Related Products. Iowa State University, PhD Dissertation. http:// lib.dr.iastate.edu/etd/14692, accessed 08/01/2019.

Leondari, A. - Gonida, E. (2007): Predicting Academic Self Handicapping in Different Age Groups: The Role of Personal Achievement Goals and Social Goals. British Journal of Educational Psychology 77: 595-611.

Lewin, K. (1939): Field Theory and Experiment in Social Psychology: Concepts and Methods. The American Journal of Sociology 44(6): 868-896.

Midgley, C. - Anderman, E. M. - Hicks, L. (1995): Differences between Elementary and Middle School Teachers and Students. Journal of Early Adolescence 15: 90-113.

Morse, J. M. (2003): Principles of Mixed Methods and Multimethod Research Design. In: Tashakkori, A. - Teddlie, C. (eds): Handbook of Mixed Methods in Social and Behavioral Research. Thousand Oaks, CA: Sage, pp. 189-208.

Neulinger, Á. (2016): Több-módszertanú és vegyes módszertanú kutatások [Multiple and Mixed Methods Research]. Vezetéstudomány 47(4): 63-66.

Rook, D. W. (1987): The Buying Impulse. Journal of Consumer Research 14(2): 189-199.

Rook, D. W. - Fisher, R. J. (1995): Normative Influences on Impulsive Buying Behavior. Journal of Consumer Research 22(3): 305-313.

Sherry, J. F. (1983): Gift Giving in Anthropological Perspective. Journal of Consumer Research 10(2): 157-168.

Smith, O. - Raymen, T. (2017): Shopping with Violence: Black Friday Sales in the British Context. Journal of Consumer Culture 17(3): 677-694.

Spiegelberg, E. (1981): The Phenomenological Movement: A Historical Introduction Phaenomenologica. Kluger Academic Publishers.

Svejnar, J. (2002): Transition Economies: Performance and Challenges. Journal of Economic Perspectives 16(1): 3-28.

Swilley, E. - Goldsmith, R. E. (2013): Black Friday and Cyber Monday: Understanding Consumer Intentions on Two Major Shopping Days. Journal of Retailing and Consumer Services 20(1): 43-50.

Tauber, E. M. (1972): Why do People Shop? Journal of Marketing 36(4): 46-59.

Teddlie, C. - Tashakkori, A. (2003): Major Issues and Controveries in the Use of Mixed Methods in the Social and Behavioral Sciences. In: Tashakkori, A. - Teddlie, C. (eds): Handbook of Mixed Methods in Social \& Behavioral Research. Thousand Oaks: Sage, pp. 3-50. 
Wakefield, K. L. - Baker, J. (1998): Excitement at the Mall: Determinants and Effects on Shopping Response. Journal of Retailing 74(4): 515-539.

Wesley, S. C. - LeHew, M. A. - Woodside, A. (2006): Consumer Decision-Making Styles and Mall Shopping Behavior: Building Theory Using Exploratory Data Analysis and the Comparative Method. Journal of Business Research 59(5): 535-548.

Westbrook, R. A. - Black, W. C. (1985): A Motivation-Based Shopper Typology. Journal of Retailing 61(1): 78-103.

Zhong, J. Y. - Mitchell, V. W. (2012): Does Consumer Well-Being Affect Hedonic Consumption? Psychology \& Marketing 29(8): 583-594.

Open Access. This is an open-access article distributed under the terms of the Creative Commons Attribution 4.0 International License (https://creativecommons. org/licenses/by/4.0), which permits unrestricted use, distribution, and reproduction in any medium, provided the original author and source are credited, a link to the CC License is provided, and changes - if any - are indicated. (SID_1) 